\title{
Perirenal haematoma with Klebsiella pneumonia pyelonephritis
}

\author{
Jennifer Mancio, ${ }^{1}$ Marco Oliveira, ${ }^{1}$ Manuel Gonçalves, ${ }^{2}$ Paula Castelões $^{2}$
}

${ }^{1}$ Department of Cardiology Thorax and Circulation Unit, Centro Hospitalar de Vila Nova de Gaia e Espinho, Vila Nova de Gaia, Portugal ${ }^{2}$ Department of Emergence and Intensive care, Centro Hospitalar de Vila Nova de Gaia e Espinho, Vila Nova de Gaia, Portugal

\section{Correspondence to} Dr Jennifer Mancio, jennimancio@gmail.com
To cite: Mancio J, Oliveira $\mathrm{M}$, Gonçalves $\mathrm{M}_{\mathrm{t}}$ et al. BMJ Case Reports Published online: [please include Day Month Year] doi:10.1136/bcr-2012007523

\section{DESCRIPTION}

An 83-year-old woman was admitted to the emergency department reporting a 3-day progressively worsening lumbar pain and fever. Her past medical history was remarkable for type 2 diabetes mellitus, class 3 chronic renal failure, repetitive urinary tract infections and hypothyroidism. On admission, the patient was pale, febrile with arterial hypotension, tachycardia and low peripheral oxygen saturation murphy renal sign was positive and the abdominal examination was normal. Laboratory results showed a severe anaemia (haemoglobin of $6 \mathrm{~g} / \mathrm{dl}$ ), leucocytosis $\left(2.6 \times 10^{4}\right.$ cells/ $\left./ \mu \mathrm{l}\right)$, haematuria and leucocyturia. Amoxicillin and clavulanic acid, as well as, red blood cells transfusion were initiated. Abdominal CT revealed an enlarged left kidney with homogenous collection inside renal capsule consistent with a moderate perirenal haematoma (figure 1). Urgent left nephrectomy was performed $24 \mathrm{~h}$ after admission because of worsen anemia and haemodinamic instability. Macroscopically, the kidney had an irregular surface with multiple blood clots adhering to the external capsule. Over the course of 24 postoperative hours, the patient remained haemodynamically unstable and, despite adequate fluid resuscitation with blood transfusion, intravenous fluids and high doses of intravenous vasopressors (norepinephrine and dopamine), the patient died due to refractory shock with multiple-organ failure. Later, the microscopic examination of nephrectomy specimen confirmed acute and chronic pyelonephritis lesions with no signs of malignancy (figure 2); urine and blood cultures identified Klebsiella pneumonia (sensitive to $\beta$-lactamics).

Perirenal haematoma may arise from a variety of situations and presentations range from mild lumbar pain to haemorragic shock. ${ }^{12}$ Although initially renal cell carcinoma was thought as the most common reason, $2.4 \%$ of cases were due to infection. ${ }^{2}$ We report a patient with $K$ pneumonia pyelonephritis complicated with perirenal haematoma who presented with shock and was operated on. The correct sequence of events is difficult to establish. Based on her chronic structural nephropathy and previous history of urinary tract infections, absence of signs of aggravated anaemia in the days before admission, we interpreted as pyelonephritis complicated with perirenal haematoma instead of haematoma secondarily infected. In this regard, the mainstay of treatment is drainage and antibiotics as an adjunct to control sepsis and to prevent the spread of infection. Percutaneous drainage should be the initial modality of treatment but, in the
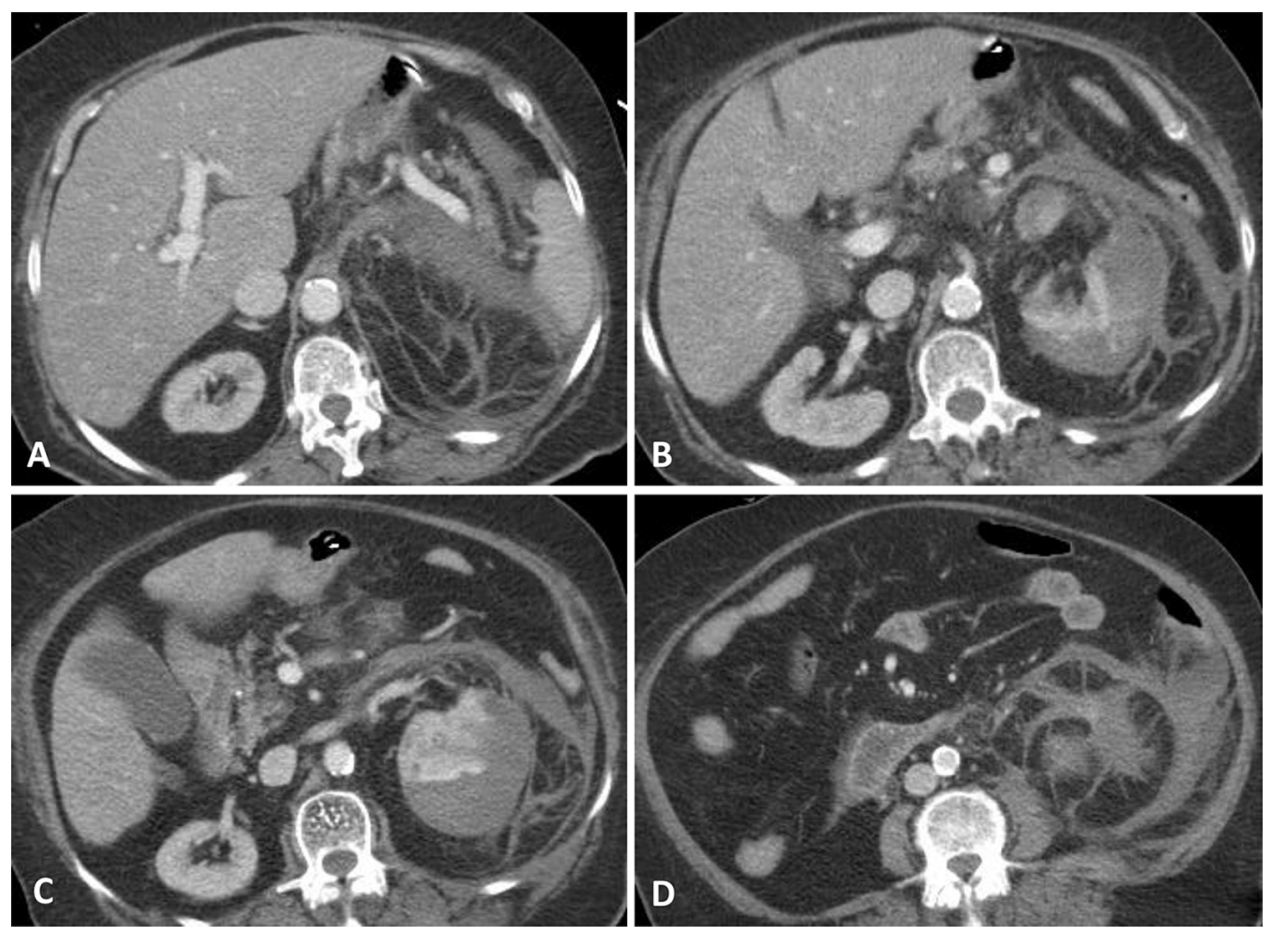

Figure 1 Abdominal CT showing an enlarged left kidney with homogenous fluid collection inside renal capsule with moderate volume; the Hounsfield unit of the collection was 50, which was suggestive of clotted blood. There was no solid component or abnormal contrast uptake in the collection (A-D). 

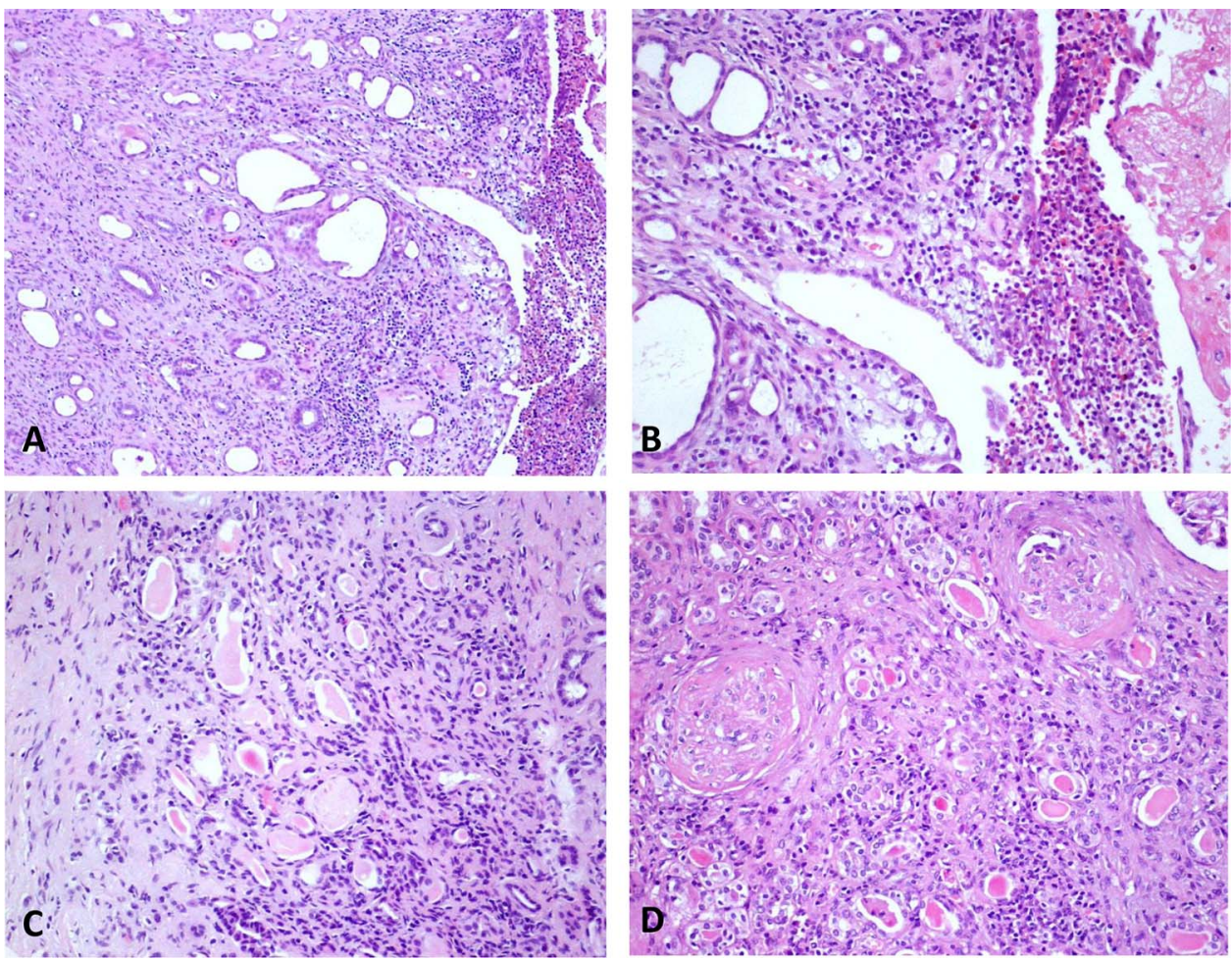

Figure 2 Microscopic appearance of acute and chronic pyelonephritis shows an acute component with suppurative inflammation (A and B) and a chronic component with tubular atrophy, lymphoplasmacytic inflammatory infiltrate and interstitial fibrosis (A-D) as well as tubular thyroidisation (B and D) and glomerulosclerosis (D).

presence of a perirenal haematoma, abscess cavities filled purulent fluid, markedly diseased non-functioning kidney and diabetes this procedure is relatively contraindicated, and in patients who are septic urgent intervention is required and nephrectomy (open or laparoscopic) is the classic treatment. ${ }^{3}$ Laparoscopic nephrectomy is difficult in cases of large renal mass, vascular anomalies or severe adhesion that occur in patients with repetitive urinary tract infection. Laparoscopic nephrectomy, especially with active infection, may be a high-risk procedure and should be, prudently, chosen. ${ }^{4}$ In our case, open nephrectomy was considered more feasible and safe than laparoscopic procedure.

\section{Learning points}

- The diagnosis of perirenal abscess is difficult based on clinical findings alone.

- Serial CT scanning to confirm the diagnosis and to screen complications is useful.

- The mainstay of treatment is drainage and antibiotics, however nephrectomy could be indicated.

- High co morbidity and delay on diagnosis are factors of worse prognosis.
Competing interests None.

Patient consent Obtained.

\section{REFERENCES}

1 Baishya RK, Dhawan DR, Sahnis RB. Spontaneous subcapsular renal hematoma: a case report and review of literature. Urol Ann 2011;3:44-6.

2 Zhang JQ, Fielding JR, Zou KH. Etiology of spontaneous perirenal hemaorrhage: a meta-analysis. J Urol 2002;167:1593-6.

3 Yen DH, Hu SC, Kao WF, et al. Renal abscess: early diagnosis and treatment. Am J Emerg Med 1999;17:192-7.

4 Manohar T, Desai M, Desai M. Laparoscopic nephrectomy for benign and inflammatory conditions. J Endourol 2007;21:1323-8

5 Meng MV, Mario LA, McAninch JW. Current treatment and outcomes of perinephric abscesses. J Urol 2002:168:1337-40. 
Copyright 2013 BMJ Publishing Group. All rights reserved. For permission to reuse any of this content visit http://group.bmj.com/group/rights-licensing/permissions.

BMJ Case Report Fellows may re-use this article for personal use and teaching without any further permission.

Become a Fellow of BMJ Case Reports today and you can:

- Submit as many cases as you like

- Enjoy fast sympathetic peer review and rapid publication of accepted articles

- Access all the published articles

- Re-use any of the published material for personal use and teaching without further permission

For information on Institutional Fellowships contact consortiasales@bmjgroup.com

Visit casereports.bmj.com for more articles like this and to become a Fellow 